\title{
Targeting RNA for processing or destruction by the eukaryotic RNA exosome and its cofactors
}

\author{
John C. Zinder ${ }^{1,2}$ and Christopher D. Lima ${ }^{2,3}$ \\ ${ }^{1}$ Tri-Institutional Training Program in Chemical Biology, Memorial Sloan Kettering Cancer Center, New York, New York 10065, \\ $\mathrm{USA}_{;}{ }^{2}$ Structural Biology Program, Sloan Kettering Institute, New York, New York, 10065, USA; ${ }^{3}$ Howard Hughes Medical \\ Institute, New York, New York, 10065 USA
}

The eukaryotic RNA exosome is an essential and conserved protein complex that can degrade or process RNA substrates in the $3^{\prime}-$ to- $^{\prime}$ direction. Since its discovery nearly two decades ago, studies have focused on determining how the exosome, along with associated cofactors, achieves the demanding task of targeting particular RNAs for degradation and/or processing in both the nucleus and cytoplasm. In this review, we highlight recent advances that have illuminated roles for the RNA exosome and its cofactors in specific biological pathways, alongside studies that attempted to dissect these activities through structural and biochemical characterization of nuclear and cytoplasmic RNA exosome complexes.

The eukaryotic RNA exosome is a conserved multisubunit protein complex that catalyzes $3^{\prime}$-to- $5^{\prime}$ processing or degradation of a vast array of different RNA substrates (Januszyk and Lima 2014; Kilchert et al. 2016). Since its discovery as a key factor involved in $3^{\prime}$ processing of ribosomal RNAs (rRNAs) during ribosome biogenesis in budding yeast (Mitchell et al. 1997), transcriptome-wide analyses in diverse eukaryotic model systems revealed that the RNA exosome contributes to the processing and/or degradation of nearly every class of RNA /Chekanova et al. 2007; Gudipati et al. 2012; Schneider et al. 2012; Pefanis et al. 2014).

Nuclear and cytoplasmic forms of the RNA exosome are defined by unique subunit compositions that interact with distinct cofactors in these subcellular compartments (Table 1). In the cytoplasm of Saccharomyces cerevisiae, the exosome includes a nine-subunit core (Exo9) that interacts with Dis3 to form a 10-subunit complex $\left(\right.$ Exo10 $\left.{ }^{\text {Dis3 }}\right)$. The Exo9 core lacks catalytic activity, while Dis3 catalyzes endoribonuclease (endo) and processive

[Keywords: $3^{\prime}$ to 5'; RNA degradation; RNA exosome; RNA processing; endoribonuclease; exoribonuclease; exosome]

Corresponding author: limac@mskcc.org

Article is online at http://www.genesdev.org/cgi/doi/10.1101/gad.294769. 116. Freely available online through the Genes \& Development Open Access option. 3'-to-5' exoribonuclease (exo) activities (Liu et al. 2006; Dziembowski et al. 2007; Lebreton et al. 2008). Although redundant with cytoplasmic 5'-to-3' decay pathways (Anderson and Parker 1998), Exo10 ${ }^{\text {Dis3 }}$ contributes to translation-dependent mRNA surveillance pathways such as nonstop decay (NSD), nonsense-mediated decay (NMD), and no-go decay (NGD) (for review, see Łabno et al. 2016). All 10 genes encoding subunits of Exo10 Dis3 are essential for viability in yeast (Mitchell et al. 1997; Brouwer et al. 2000). While dis3 alleles that disrupt its endo activity bear few phenotypic defects, mutations that disrupt its exo activity result in slow growth, and mutations that disrupt both activities result in synthetic growth defects or inviability (Lebreton et al. 2008). In the nucleus, Exo10 ${ }^{\text {Dis3 }}$ associates with a distributive $3^{\prime}$-to-5' exoribonuclease Rrp6 and its obligate binding partner, C1D, to form a 12 component complex (Exo12 $2^{\text {Dis3/Rrp6/C1D) }}$ (Allmang et al. 1999b; Feigenbutz et al. 2013). While Rrp6 is not essential, $\Delta$ rrp6 strains display a slow growth phenotype, temperature sensitivity, and RNA processing defects (Briggs et al. 1998; Allmang et al. 1999a,b).

Subunit compositions of nuclear and cytoplasmic RNA exosomes from humans resemble yeast, with some notable differences. For instance, humans encode two exosome-associated Dis3 enzymes, DIS3 and DIS3L, that localize to the nucleus and cytoplasm, respectively (Staals et al. 2010; Tomecki et al. 2010). Similar to yeast, human DIS3 and DIS3L catalyze processive exo activity, although only DIS3 has an intact endonuclease site. DIS3 is excluded from the nucleolus in human cells, while RRP6 is localized to the nucleus and enriched in the nucleolus (Targoff and Reichlin 1985; Staals et al. 2010; Tomecki et al. 2010), suggesting that the nuclear RNA exosome in humans includes Exo9, DIS3, and RRP6/C1D (Exo12 ${ }^{\text {DIS3/RRP6/C1D }) ~}$ and that a nucleolar exosome may include Exo9 and RRP6 as the only nuclease, presumably associated with C1D (Exo11 ${ }^{\text {RRP6/C1D }) . ~ M a m m a l i a n ~ c e l l s ~ l a c k i n g ~ D I S 3 ~ c a n-~}$ not grow, and mutations that disrupt both DIS3 exo and

(C) 2017 Zinder and Lima This article, published in Genes \& Development, is available under a Creative Commons License (Attribution 4.0 International), as described at http://creativecommons.org/licenses/by/4.0/. 
Table 1. RNA exosome and cofactors

\begin{tabular}{llll}
\hline & Human gene & & Protein names \\
\hline S1/KH cap & EXOSC1 & Cs14, Ski4 & Localization \\
& EXOSC2 & Rrp4 & Nucleus/cytoplasm \\
& EXOSC3 & Rrp40 & Nucleus/cytoplasm \\
PH-like ring & EXOSC4 & Rrp41, Ski6 & Nucleus/cytoplasm \\
& EXOSC5 & Rrp46 & Nucleus/cytoplasm \\
& EXOSC6 & Mtr3 & Nucleus/cytoplasm \\
& EXOSC7 & Rrp42 & Nucleus/cytoplasm \\
& EXOSC8 & Rrp43 & Nucleus/cytoplasm \\
EXOSC9 & Rrp45, PM/Scl-75 & Nucleus/cytoplasm \\
Processive 3'-5' exoribonuclease, & DIS3 & Dis3, Rrp44 & Nucleus \\
endonuclease & & Nucleus (yeast), nucleoplasm (humans) \\
Processive 3'-5' exoribonuclease & DIS3L1 & Dis3L1 & Cytoplasm \\
Exosome cofactor & C1D & C1D, Rrp47, Lrp1 & Nucleus \\
Exosome cofactor & MPP6 & Mpp6 & Nucleus (yeast), nucleolus (human) \\
Exosome cofactor & HBS1L & HBS1L (isoform 3, humans), & Cytoplasm \\
Ski complex & & Ski7 (yeast) & Cytoplasm \\
& SKIV2L & Ski2 helicase & Cytoplasm \\
TRAMP complex & TTC37 & Ski3 & Cytoplasm
\end{tabular}

endo activities are synthetic-lethal in HeLa cells, indicating that DIS3 activities are not redundant with other RNA decay pathways (Tomecki et al. 2014).

This review focuses on recent developments pertaining to the diverse biological functions of the exosome and our current understanding of how its structure and biochemical activities enable it to achieve these functions. This will include a brief survey of newly uncovered biological roles for the RNA exosome as well as an overview of our current knowledge for the structural basis of interactions between exosomes, RNA substrates, and cofactors that influence its processing and/or degradation activities.

\section{The RNA exosome and its roles in cellular homeostasis}

Because the RNA exosome is essential for viability in single-celled organisms, it is perhaps unsurprising that it contributes to important and diverse biological processes in higher eukaryotes and is mutated in several diseases (for review, see Staals and Pruijn 2010; Fabre and Badens 2014; Robinson et al. 2015). Here we review recent advances in our understanding of how the exosome and its cofactors contribute to proliferation, differentiation, innate immunity against RNA viruses, and telomerase activity.

\section{Proliferation and differentiation}

Dis3 has gained notoriety for its role in cellular proliferation and was identified as one of the most highly mutated genes in genome-wide association studies of multiple myeloma (MM) (Chapman et al. 2011; Walker et al. 2012; Lohr et al. 2014). Most mutations observed in these studies cluster within its exoribonuclease domain and are pre- dicted to disrupt its $3^{\prime}$-to- $5^{\prime}$ decay activity. As Dis3 activities are generally associated with promoting cell division (Ohkura et al. 1988; Tomecki et al. 2014), inactivation of Dis3 in MM was somewhat perplexing. A recent study addressed this by characterizing inactivating mutations of Dis3 in Drosophila, Caenorhabditis elegans, and mouse models (Snee et al. 2016). While mutating Dis3 alone resulted in mitotic defects, increased RAS activities acted synergistically with this mutant to stimulate growth, a phenotype that was not evident using activated RAS alone. This perhaps explains the observation that RAS activities were often increased in MM clones that contained inactivating Dis3 mutations (Lohr et al. 2014). Furthermore, another study depleted Dis3 in human $\mathrm{MM}$ and other cell lines and observed accumulation of Let $28 \mathrm{Bp}$, a protein that sequesters the let-7 family of microRNAs (miRNAs) to prevent their maturation (Segalla et al. 2015). Because let-7 RNAs can silence $M Y C, R A S$, and other mRNAs, Dis3 depletion ultimately results in accumulation of these gene products, potentially explaining correlations observed for Dis3 inactivation and RAS activation in model systems (Snee et al. 2016) and MM (Lohr et al. 2014). Perhaps consistent with this model, decreased Dis3 expression has been observed for high-risk genotypes associated with pancreatic cancer (Hoskins et al. 2016), where activating RAS mutants are common (Eser et al. 2014).

Recent work has also illuminated a role for the exosome during erythropoiesis, the process through which hematopoietic stem cells differentiate into erythrocytes (McIver et al. 2014, 2016). In this process, the balance between hematopoietic stem cell differentiation and proliferation is critical: Proliferation can lead to tumor formation, while differentiation can exhaust the supply of stem cells. For 
erythropoiesis, proliferation and terminal differentiation are enforced by stem cell factor (SCF) and erythropoietin, respectively. GATA-1 and Foxo-3 are master transcription factors that control differentiation during erythropoiesis, and both down-regulate expression of Exosc8, an Exo9 subunit (Table 1). Interestingly, shRNA knockdown of exosome core subunits in hematopoietic stem cells resulted in an accumulation of GATA-1- and Foxo-3-regulated transcripts, suggesting that the exosome may counter differentiation by degrading these transcripts in the absence of erythropoietin (McIver et al. 2014), similar to a role proposed for the exosome in maintaining a proliferative state in human skin stem cells via selective targeting of the GRLH mRNA (Mistry et al. 2012). Furthermore, hematopoietic stem cells depleted of exosome components were nonresponsive to SCF due to decreased levels of its cognate receptor tyrosine kinase, Kit, although they remained responsive to erythropoietin (McIver et al. 2016).

\section{Viral defense}

A role for the exosome and its cofactors in viral defense was described nearly two decades before its discovery through a genetic screen that identified the "SKI" genes in $S$. cerevisiae. These genes were so named because of the "superkiller" phenotype observed: Mutations in SKI genes increased levels of a killer toxin that was produced by the M viral dsRNA (Toh-E et al. 1978; Ridley et al. 1984). It was later discovered that three of these proteins (Ski2, Ski3, and Ski8) form the Ski complex (Brown et al. 2000) that interacts with the RNA exosome via another protein, Ski7 (van Hoof et al. 2000; Araki et al. 2001). Other SKI genes were later identified as subunits of the exosome itself (Table 1).

A more recent study using cultured human cells revealed a role for the Ski complex in antiviral defense against hepatitis B virus (HBV) (Aly et al. 2016). A screen for helicases that could suppress HBV replication identified the human Ski complex RNA helicase SKIV2L (Table 1). They further demonstrated that interactions between the HBV X-RNA, SKIV2L, HBS1L (recently identified as the human Ski7 homolog), and the exosome resulted in selective degradation of the HBV X-RNA via the NSD pathway.

The Trf-Air-Mtr4 polyadenylation (TRAMP) complex is a set of cofactors that prepares RNA substrates for degradation by the nuclear RNA exosome (see below; Table 1; LaCava et al. 2005; Wyers et al. 2005); however, this complex was recently shown to participate in viral defense in the cytoplasm (Molleston et al. 2016). Infection of human and Drosophila cells with the disparate RNA viruses vesicular stomatitis virus, Sindbis virus, or Rift Valley fever virus (RVFV) was potentiated by knockdown of exosome and TRAMP components. While normally restricted to the nucleus (Lubas et al. 2011), subunits of the TRAMP complex are exported to the cytoplasm during infection, where they participate in the degradation of viral RNAs (Molleston et al. 2016). Furthermore, appending a 3' untranslated region (UTR) from RVFV to a GFP reporter was sufficient to stimulate its degradation upon RVFV infec- tion in human cells, suggesting that viral RNAs are targeted for selective degradation under these conditions. The mechanisms underlying TRAMP export to the cytoplasm and targeting of viral $3^{\prime}$ UTRs await further investigation.

\section{Telomerase RNA (hTR) quality control}

Several recent studies implicated the exosome and its cofactors in degradation and quality control of hTR in HeLa cells (Nguyen et al. 2015a; Tseng et al. 2015; Shukla et al. 2016). Degradation of hTR is stimulated by the $3^{\prime}$ polyadenylation activity of the human TRAMP complex and antagonized by the poly(A)-binding protein PABPN1 and the deadenylase PARN, which is mutated in some cases of the premature aging disease dyskeratosis congenita (DKC). One study further showed that knockdown of nuclear RNA decay machinery could rescue hTR levels and defects in telomerase activity in cells depleted of dyskerin, a protein subunit of the telomerase RNP that is also mutated in $\mathrm{DKC}$, prompting the investigators to suggest that the exosome could be a therapeutic target for certain telomere pathologies (Shukla et al. 2016).

DGCR8, a dsRNA-binding protein involved in miRNA biogenesis, has been implicated recently as an adaptor protein for exosome targeting to structured substrates such as hTR (Macias et al. 2015). DGCR8 contains dsRNA-binding and heme domains, which interact with the stem and apical regions of the pri-miRNA, respectively, as a dimer (Nguyen et al. 2015b). In the nucleoplasm, this dimer interacts with DROSHA, an RNA endonuclease involved in miRNA maturation, to ensure its fidelity in producing miRNAs (for review, see Macias et al. 2013). Investigators found that DGCR 8 also interacts in a distinct complex with the nucleolar exosome, and this interaction is necessary for the turnover of snoRNAs and hTR in that compartment (Macias et al. 2015).

\section{RNA exosome structure and activities and RNA paths to enzymatic subunits}

While the structure of the human Exo9 core was obtained more than a decade ago, more recent crystal and cryo-electron microscopy (cryo-EM) structures have revealed architectures for intact yeast cytoplasmic and nuclear RNA exosomes in complex with RNA substrates and cofactors. Combined with biochemical and genetic studies, these structures illuminate roles for the noncatalytic core in modulating the activities of the associated ribonucleases and the impact of RNA path selection with respect to the fate of RNA substrates.

\section{RNA exosome core and catalytic subunits}

The architecture of the exosome core and its similarity to bacterial and archaeal RNases have been reviewed recently (Januszyk and Lima 2014). Briefly, the Exo9 core includes a hexameric ring of six RNase PH-like domaincontaining proteins (Rrp41, Rrp42, Rrp43, Rrp45, Rrp46, and Mtr3; the PH-like ring). This ring is capped by a ring 
of three proteins that are collectively termed the $\mathrm{S} 1 / \mathrm{KH}$ cap because two proteins harbor an $\mathrm{N}$-terminal domain (NTD), S1 domain, and KH domain (Rrp4 and Rrp40), and the third includes the NTD, S1 domain, and C-terminal domain (CTD; Cs14). Together, Exo9 forms a noncatalytic doughnut-shaped complex with a prominent central channel that is wide enough to accommodate ssRNA (Fig. 1; Table 1; Liu et al. 2006).

Catalytic subunits of the RNA exosome include Rrp6 and at least one isoform of Dis3. Dis3 and Dis3L (in the cytoplasm of higher eukaryotes) include an active site that catalyzes processive $\mathrm{Mg}^{2+}$-dependent hydrolytic $3^{\prime}$-to-5' exoribonuclease activity (Dziembowski et al. 2007; Staals et al. 2010; Tomecki et al. 2010; Makino et al. 2013). Dis3 from yeast and humans includes a second active site in the PilT N-terminal (PIN) domain that catalyzes distributive $\mathrm{Zn}^{2+} / \mathrm{Mn}^{2+}$-dependent endoribonuclease activity (Lebreton et al. 2008; Schneider et al. 2008; Schaeffer et al. 2009). Dis3 enzymes associate with exosome PH-like ring subunits opposite to their surfaces that interact with the S1/KH cap (Fig. 1; Bonneau et al. 2009). The nuclear subunit Rrp6 includes a single active site that catalyzes $\mathrm{Mg}^{2+}$-dependent distributive $3^{\prime}$-to-5' hydrolytic exoribonuclease activity (Targoff and Reichlin 1985; Burkard and Butler 2000). The catalytic domain of yeast Rrp6 rests atop the Exo9 core using surfaces opposite to that used by Dis3 (Fig. 1; Wasmuth et al. 2014).

An early hypothesis proposed that RNA degradation by the exosome was conceptually similar to protein degradation by the proteasome (van Hoof and Parker 1999). In this model, the respective active sites are sequestered from the cellular milieu to prevent spurious degradation, and purposeful degradation requires that substrates be licensed to gain access to the active sites through a restricted channel. Subsequent biochemical, structural, and genetic studies largely confirmed this hypothesis, including the observation that Rrp6 and Dis 3 activities were modulated or inhibited when associated with the Exo9 core (Dziembowski et al. 2007; Bonneau et al. 2009; Wasmuth and Lima 2012) and that various surfaces within the Exo9 central channel were important for guiding RNA to the respective active sites (Wasmuth and Lima 2012, 2017; Drazkowska et al. 2013; Wasmuth et al. 2014). Subsequent structures also support these models. RNA can thread through the Exo9 central channel to reach Dis3 for processive degradation (Makino et al. 2013; Kowalinski et al. 2016; Liu et al. 2016) or can be deflected back to the Rrp6 active site for distributive processing or degradation (see below; Fig. 1C,D; Wasmuth et al. 2014; Zinder et al. 2016).

\section{Yeast Dis3 conformations and RNA paths}

Structures of $S$. cerevisiae RNA exosome complexes with Dis3 revealed two prominent conformations for the enzyme (Bonneau et al. 2009; Makino et al. 2013, 2015; Liu et al. 2014, 2016; Zinder et al. 2016). While the PIN domain, which contacts the PH-like proteins Rrp41 and Rrp45, remains static, the exoribonuclease module rotates nearly $120^{\circ}$ between the two conformations (Fig. $1 \mathrm{~B}, \mathrm{C})$. One conformation can bind short ssRNAs $\mid<14$ nucleotides [nt]), bypassing the Exo9 central channel (termed the direct access Dis3 conformation) (Fig. 1B). This

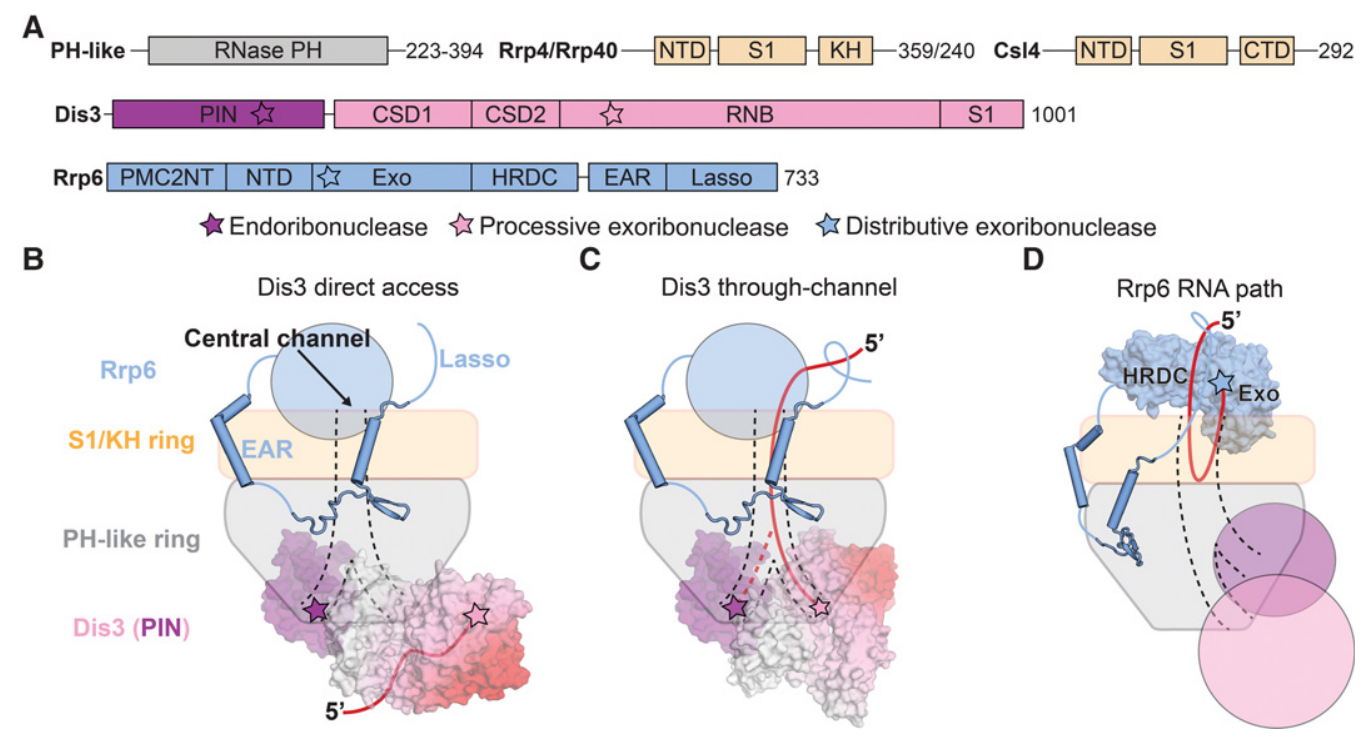

Figure 1. RNA paths and Dis3 conformations in the yeast nuclear exosome. (A) Domain schematics for $S$. cerevisiae nuclear exosome components. Catalytic sites are represented by stars, and amino acid lengths for the $S$. cerevisiae proteins are indicated. $(B)$ Direct access conformation of Dis3. Dis3 and the Rrp6 exosome-associated region (EAR) domain are from Protein Data Bank (PDB) 5K36. The central channel is indicated by black dashed lines, including a speculative path to the Dis3 endonuclease site, and RNA is represented as a red line with the $5^{\prime}$ end indicated. (C) Through-channel conformation of Dis3. Dis3 is from PDB 4IFD, and the Rrp6 EAR domain is from PDB 5K36. RNA and the central channel are indicated as previously, with the dashed red line representing a speculative RNA path to the Dis3 endo active site. $(D)$ Rrp6 catalytic module (from PDB 5K36) bound to the core with RNA in its active site. The RNA path to Rrp6 is based on biochemical data and PDB 5K36. 
conformation features an extensive interaction surface with Exo9 and is also observed in the absence of RNA, suggesting that it is the resting state of the RNA exosome (Bonneau et al. 2009; Liu et al. 2014, 2016). The other conformation is observed when Dis3 binds longer RNAs |>24 nt) that can span the Exo9 central channel (termed the through-channel conformation) (Fig. 1C; Makino et al. 2013; Liu et al. 2014). This conformation features fewer interactions with Exo9 and is thought to be stabilized by the presence of long RNAs (Liu et al. 2016). Additionally, biochemical data support a through-channel RNA path to the Dis3 endonuclease site, although this model lacks structural confirmation (Wasmuth and Lima 2012; Drazkowska et al. 2013).

The potential importance for these two Dis3 conformations was underscored by two recent studies (Han and van Hoof 2016; Zinder et al. 2016). In one case, investigators analyzed the in vivo effects in a strain expressing a dis3 allele that contained point mutations predicted to destabilize the direct access Dis3 conformation (Han and van Hoof 2016). Among many observations, they showed that cells expressing this dis3 allele were viable, albeit with a slow growth phenotype and defects in the degradation of structured substrates. Perhaps most intriguing was the observation that this dis 3 allele suppressed the growth defects/lethality of mutations designed to occlude the Exo9 central channel (Wasmuth and Lima 2012), suggesting strong genetic interactions between mutations in the Exo9 core and Dis3. In the second study, the in vitro effects for mutations within Exo9 subunits predicted to disrupt contacts to Dis3 in both conformations were analyzed (Zinder et al. 2016). Deletions of regions of Rrp45 and Rrp43 proteins that interacted with the direct access Dis3 conformation resulted in reconstituted exosome complexes with increased Dis3 activity. Conversely, deleting a portion of Rrp43 that interacted with the through-channel Dis3 conformation resulted in a measurable decrease in activity. Furthermore, deletion of both Rrp43 elements suppressed the effects of either, suggesting that Exo9 contacts to Dis3 can modulate its activities by stabilizing one or the other Dis3 conformation. The elements in the Exo9 core that make conformation-specific contacts to Dis3 are unique to budding yeast proteins, so it remains unclear whether other eukaryotic exosomes modulate Dis3 activities by similar means.

\section{Rrp6 conformations and RNA paths}

Rrp6 is tethered to the Exo9 core through a C-terminal exosome-associated region (EAR) that wraps around the $\mathrm{S} 1 / \mathrm{KH}$ cap and $\mathrm{PH}$-like ring (Fig. 1). In several structures, its catalytic domain is positioned atop the Exo9 core via interactions between the Rrp6 helicase and RNase D CTD (HRDC) and Exo domain and a conserved surface on the S1/KH ring near the entrance to the central channel (Fig. 1D; Wasmuth et al. 2014; Makino et al. 2015; Zinder et al. 2016). However, the catalytic module of Rrp6 can be displaced at equilibrium if a structured RNA with a $3^{\prime}$ overhang long enough to reach a catalytically inactivated Dis3 is present (Makino et al. 2015).
A model in which RNA accesses the Rrp6 catalytic site via interactions with the $\mathrm{S} 1 / \mathrm{KH}$ ring proteins is supported by UV cross-linking, biochemical analysis of complexes with mutant S1/KH or Rrp6 subunits (Wasmuth and Lima 2012, 2017), and two recent structures. These structures show the $3^{\prime}$ end of RNA anchored to the Rrp6 active site, with the RNA path directed toward the S1/KH region of the central channel. While the remaining RNA was disordered in an earlier structure (Wasmuth et al. 2014), a more recent model showed that RNA can be deflected by the $\mathrm{S} 1 / \mathrm{KH}$ ring to position its $5^{\prime}$ end near a channel formed between the HRDC and Exo domains of Rrp6 (Fig. 1D; Zinder et al. 2016).

While some models suggest that Rrp6 plays a passive role during Dis3-mediated RNA decay (Makino et al. 2015), other data suggest that Rrp6 can enhance Dis3 activities in the nuclear RNA exosome. One line of evidence supporting this is that degradation of poly $(\mathrm{A})^{+}$transcripts that accumulate in yeast strains lacking Rrp6 can be partially rescued by expressing catalytically inert Rrp6 (Assenholt et al. 2008; Mukherjee et al. 2016). Furthermore, in vitro studies showed that Rrp6 protein can activate the RNA decay activities of Dis3, especially evident for substrates with poly(A) tails (Wasmuth and Lima 2012, 2017; Wasmuth et al. 2014). Interestingly, Dis3 activation requires two domains of Rrp6, its catalytic Exo/HRDC module and its C-terminal tail, termed the RNA lasso (Fig. 1; Wasmuth and Lima 2017). While the catalytic domain binds the $\mathrm{S} 1 / \mathrm{KH}$ ring to presumably widen the central channel, the C-terminal domain binds RNA to enhance Rrp6 and Dis3 activities on a variety of RNA substrates. Although disordered in all available structures, it is perhaps noteworthy that the RNA lasso is positioned near the top of the Exo9 core, where it could assist binding RNA adjacent to the central channel (Fig. 1B-D).

\section{TRAMP and Ski complexes}

The previous section focused on structure/activity relationships for the RNA exosome as a standalone machine; however, it is likely that exosome cofactors mediate most encounters between RNA substrates and the RNA exosome. Recent studies focused on mechanisms that recruit these cofactors to the exosome and how their various activities influence RNA decay. We restrict discussion in this section to the TRAMP and Ski complexes, as they are important and conserved modulators of RNA exosome activities in the nucleus and cytoplasm, respectively. Intact structures of TRAMP or Ski complexes bound to the exosome are not available, but structures of individual components or subcomplexes combined with genetic and biochemical studies support models as presented in Figures 2 and 3 .

\section{The TRAMP complex}

The TRAMP complex was initially uncovered by analysis of a temperature-sensitive mutant of $S$. cerevisiae that expressed hypomodified $\mathrm{tRNA}_{\mathrm{i}}^{\mathrm{Met}}$ whose phenotype was 
A

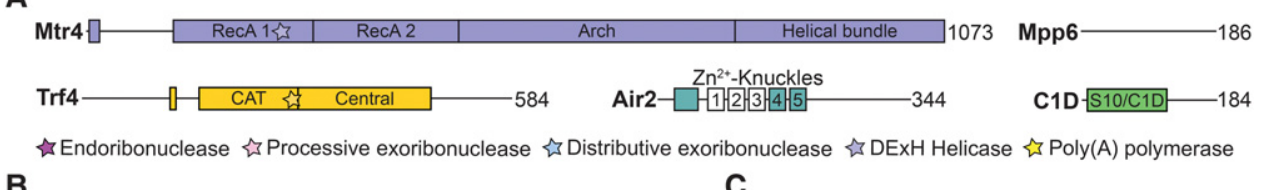

B

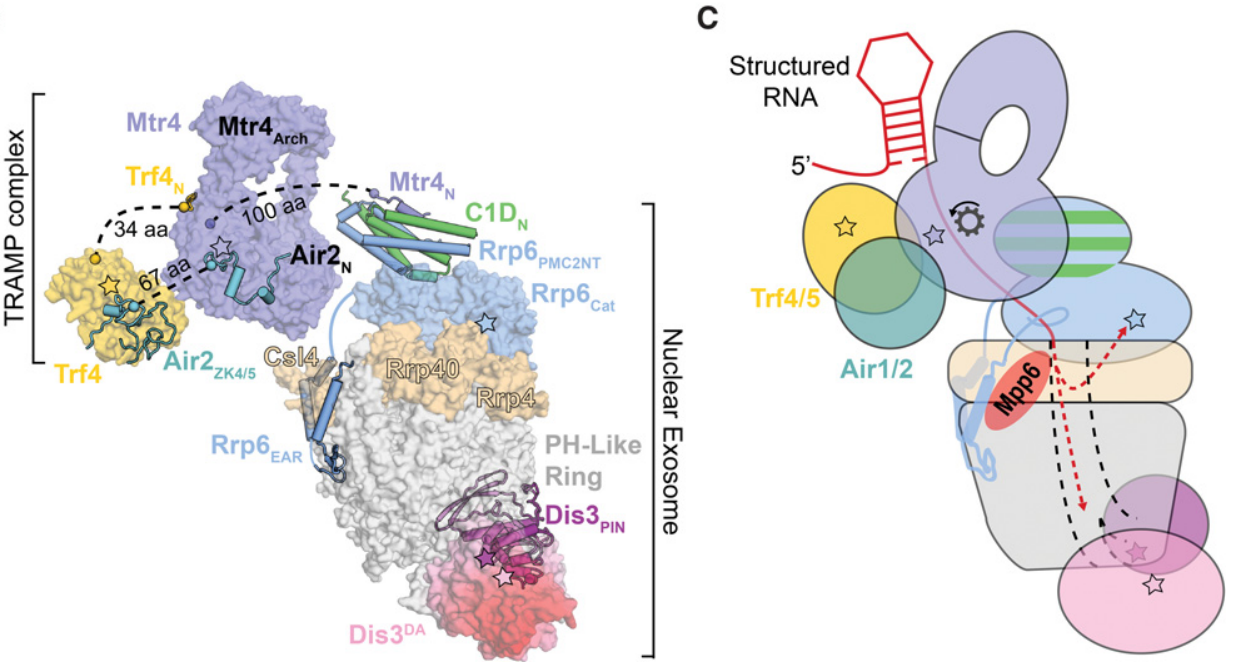

Figure 2. The TRAMP complex and the nuclear exosome. (A) Domain schematics for S. cerevisiae C1D, Mpp6, and TRAMP components. Catalytic sites are indicated by stars, and amino acid lengths for the $S$. cerevisiae proteins are shown. $(B)$ Structural models for the nuclear exosome and associated cofactors, with RNA omitted for clarity. Black dotted lines represent connecting regions for which no structural information is available. Mtr4 and Trf4/Air2 peptides are from PDB 4U4C; Trf4/Air2 zinc knuckles are from PDB 3NYB; the PH-like ring, Rrp40, Rrp4, Cs14, Dis3, the Rrp6 catalytic module, and the Rrp6 EAR are from PDB 5K36; the Rrp6 PMC2NT domain, C1D, and the Mtr4 N-terminal peptide are from PDB 4WFD and were positioned based on PDB 5C0W. (C) Model for Mtr4 threading of RNA to the nuclear exosome after polyadenylation by Trf4/5. The central channel is indicated by black dashed lines, and RNA is represented as a red line with the $5^{\prime}$ end indicated. Dashed red arrows represent RNA paths to the catalytic subunits. Helicase direction is indicated by a gear and arrow.

suppressed by mutations in a noncanonical nuclear poly (A) polymerase (Kadaba et al. 2004). This polymerase (Trf4) and its paralog (Trf5) were found to exist in complexes with either of two zinc knuckle proteins, Air1 or Air2, and the DExH helicase Mtr4 (Fig. 2; LaCava et al. 2005; Vanacova et al. 2005; Wyers et al. 2005). TRAMP is thought to assist nuclear degradation in yeast, including decay of cryptic unstable transcripts (CUTs) and processing of rRNAs (LaCava et al. 2005; Wyers et al. 2005). The TRAMP complex genetically interacts with the RNA exosome to promote RNA degradation via its $3^{\prime}$ nontemplated poly(A) polymerase and RNA helicase activities and physically via interactions between the helicase and exosome (Chen et al. 2001; Schuch et al. 2014). While Mtr4 is essential and likely integrated into other complexes, an mtr4 allele that lacks ATP-binding activity fails to rescue the lethality of a $\Delta m t r 4$ strain (Taylor et al. 2014). With respect to TRAMP, Air1/Air2 are dispensable for viability (LaCava et al. 2005); however, simultaneous deletion of trf4 and trf5 results in lethality (Castaño et al. 1996). These observations underscore the importance of a functioning TRAMP complex for nuclear RNA exosome function and for viability.

Crystal structures of Mtr4 revealed a multidomain helicase core that resembles the archaeal DNA repair helicase Hel308, with a flexible insertion termed the arch domain that is specific to Mtr4 and Ski2 helicases (Fig. 2; Jackson et al. 2010; Weir et al. 2010). Biochemical and structural studies showed that Trf and Air proteins form a stable heterodimer that interacts with the helicase core of Mtr4 via short peptide motifs (Fig. 2B; LaCava et al. 2005; Hamill et al. 2010; Falk et al. 2014; Losh et al. 2015). We presume that the polyadenylation activities of TRAMP are important for generating $3^{\prime}$ single-stranded tails that are long enough to be captured by Mtr4, thus facilitating further unwinding to produce $3^{\prime}$ single-stranded tails that are long enough to be threaded into the RNA exosome central channel (Fig. 2C).

\section{Nuclear cofactors that bridge Mtr4 and the exosome}

C1D (or Rrp47) is a small protein with functions in RNA metabolism (for review, see Mitchell 2010) and the DNA damage response (for review, see Jackson et al. 2016). While often referred to as a nuclear exosome cofactor, the recent observations that $\mathrm{C} 1 \mathrm{D}$ is present in approximately stoichiometric amounts in endogenous nuclear complexes and is critical for stable Rrp6 expression support its inclusion as a primary subunit of the nuclear exosome (Feigenbutz et al. 2013; Shi et al. 2015). A structure of the nuclear exosome bound to $\mathrm{C} 1 \mathrm{D}$ revealed interactions with the N-terminal PMC2NT domain of Rrp6 and its position above the Rrp6 catalytic module, forming a "lid" above the exosome (Fig. 2B; Makino et al. 2015). 




Figure 3. The Ski complex and the cytoplasmic exosome. (A) Domain schematics for S. cerevisiae Ski complex components. Catalytic sites are represented by stars, and amino acid lengths for the $S$. cerevisiae proteins are shown. $(B)$ Structural models for the cytoplasmic exosome and associated cofactors, with RNA omitted for clarity. Black dotted lines represent connecting regions for which no structural information is available. The Ski3, Ski8, and Ski2 N termini are from PDB 4BUJ; the Ski2 globular region and insertion are from PDB 4A4Z and were aligned to PDB 4BUJ; the Ski7 CTDs are from PDB 4ZKE; the PH-like ring, Rrp40, Rrp4, Cs14, Dis3, and the Ski7 EAR are from PDB 5JEA. (C) Model for Ski complex channeling of a translating mRNA to the cytoplasmic exosome. The central channel is indicated by black dashed lines, and RNA is represented as a red line with the $3^{\prime}$ end shown bound to the Rrp44 exonuclease active site. Helicase direction is indicated by a gear and arrow.

The composite interface between Rrp6 and C1D binds a small peptide motif near the $\mathrm{N}$ terminus of Mtr4, providing a physical tether to the exosome (Fig. 2B; Schuch et al. 2014), while the C-terminal region of C1D interacts with protein components of box C/D snoRNPs (Costello et al. 2011). With that said, the NTD of C1D fully rescues growth in synthetic-lethal $\Delta r e x 1 \Delta r r p 47$ and $\Delta m p p 6 \Delta r r p 47$ $S$. cerevisiae strains, suggesting that the most critical functions for C1D may pertain to Mtr4/TRAMP recruitment and stabilization of Rrp6 (Costello et al. 2011; Garland et al. 2013).

Mpp6 is another small, nucleic acid-binding protein that associates with the Exo9 core; however, it is estimated to be present in $10 \%$ of nuclear complexes in S. cerevisiae (Schilders 2005; Schuch et al. 2014; Shi et al. 2015). Cross-linking experiments coupled to mass spectrometry showed that it contacts the $\mathrm{S} 1 / \mathrm{KH}$ protein $\mathrm{Rrp} 40$ in the yeast complex (Shi et al. 2015), and competition binding experiments at high concentrations reported low-affinity interactions between its C-terminal region and the Rrp6 catalytic domain (Kim et al. 2016). Human Mpp6 interacts directly with Mtr4 (Chen et al. 2001), supporting a role in recruitment of Mtr4 or Mtr4 complexes in higher eukaryotes. This role may also be conserved in S. cerevisiae, as interactions between the $\mathrm{N}$ terminus of Mtr4 and the Rrp6/C1D lid are relatively weak (Schuch et al. 2014).

\section{The Ski complex}

The cytoplasmic Ski complex consists of the DExH-box helicase Ski2, the tetratricopeptide repeat scaffold protein Ski3, and two copies of the $\beta$-propeller protein Ski8p (Fig. 3; Brown et al. 2000; van Hoof et al. 2000; Halbach et al. 2013). The Ski complex contributes to mRNA turnover, degradation of aberrant mRNAs, viral defense, and RNAi pathways in some eukaryotes (for review, see Łabno et al. 2016). Deletion of any subunit of the Ski complex in S. cerevisiae results in synthetic lethality when combined with mutations of decapping enzymes or deletion of the $5^{\prime}$-to-3' exoribonuclease Xrn1 (Anderson and Parker 1998; van Hoof et al. 2000; Araki et al. 2001). Ski2 contains an $\mathrm{N}$-terminal region that is necessary for Ski complex interactions followed by a helicase core and a flexible insertion domain, similar to features observed in Mtr4 (Fig. 3; Wang et al. 2005; Halbach et al. 2012, 2013). Association of the Ski complex with the exosome extends the through-channel RNA path to Dis3 by $\sim 10 \mathrm{nt}$, leading to a model for channeling (Fig. 3C; Halbach et al. 2013). A recent cryo-EM structure of the Ski complex bound to the ribosome translating an mRNA with a $3^{\prime}$ overhang showed that the Ski complex binds the small subunit (SSU) of the ribosome via interactions between the Ski2 insertion and helicase core 
domains and one of the Ski8 protomers (Fig. 3C; Schmidt et al. 2016).

\section{Ski7/HBS1Lv3 bridges the Ski complex and RNA exosome}

Yeast Ski7 contains a globular C-terminal GTPase domain that is proposed to interact with the ribosome and NTDs that bridge the RNA exosome and Ski complexes (Araki et al. 2001; van Hoof et al. 2002; Wang et al. 2005). A crystal structure of the C-terminal module of $S$. cerevisiae Ski7 revealed its structural similarity to active translational GTPases, although GTPase activity could not be confirmed in vitro (Kowalinski et al. 2015). Aligned two-dimensional (2D) class averages from cryoEM analysis of endogenous $S$. cerevisiae Ski7-containing cytoplasmic exosome complexes suggest that the C-terminal globular domains of Ski7 adopt multiple conformations when bound to the exosome, and three-dimensional (3D) reconstructions revealed that the Ski7 NTD interacts with the Exo9 core via surfaces that overlap with those used by the Rrp6 CTD (Liu et al. 2016). This latter result was confirmed with binding assays and observed in a contemporaneous crystal structure (Kowalinski et al. 2016; Liu et al. 2016). Additionally, two groups independently identified a short splicing isoform of human HBS1L (HBS1Lv3) as the long sought after Ski7 homolog and confirmed its ability to interact with the human exosome and Ski complex (Kalisiak et al. 2016; Kowalinski et al. 2016). The canonical HBS1L isoform in humans contains a Cterminal GTPase fold that the exosome-interacting isoform lacks but does not interact with the exosome, suggesting that multiple subcomplexes of the Ski complex may exist in higher eukaryotes.

\section{Targeting RNAs to the exosome and associated complexes}

The RNA exosome can cooperate with its cofactors to specifically target transcripts for degradation. Selective targeting has reported roles in diverse processes such as heterochromatic silencing, suppression of untimely meiosis in Schizosaccharomyces pombe, and viral defense (Harigaya et al. 2006; Lee et al. 2013; Aly et al. 2016; Molleston et al. 2016). Since targeting of RNA for degradation by the exosome based on RNA sequence elements was covered in a recent review (Kilchert et al. 2016), we discuss alternative mechanisms of RNA targeting in this final section.

\section{Cofactor-mediated bridging to the cap-binding complex}

In addition to TRAMP, human MTR4 (also called SKIV2L2) is present in at least two other complexes, the nuclear exosome targeting (NEXT) and poly(A) tail exosome targeting (PAXT) complexes (Lubas et al. 2011; Meola et al. 2016). These complexes include mutually exclusive interactions between MTR4, a zinc finger protein (ZCCHC8 in NEXT and ZFC3H1 in PAXT), and a RNA- binding protein (RBM7 in NEXT and PABPN1 in PAXT). The NEXT complex promotes degradation of PROMPTs and $3^{\prime}$ extended RNAs, including aberrant hTR, in the nucleoplasm (Preker et al. 2008; Lubas et al. 2011; Tseng et al. 2015). A recent study showed that ZCCHC8 interacts with the RNA recognition motif (RRM) domain of RBM7 via a proline-rich sequence and bridges interactions with MTR4 in the complex (Falk et al. 2016). PAXT promotes degradation of longer and more mature [with respect to poly(A) tail length] substrates compared with NEXT substrates (Meola et al. 2016). Both NEXT and PAXT interact with the cap-binding complex containing ARS2 (CBCA complex) via an adaptor protein, ZC3H18, physically tethering the exosome to nascent capped transcripts to promote degradation following termination (Andersen et al. 2013; Meola et al. 2016).

In S. pombe, a nuclear Mtr4-like helicase, Mtl1, associates with a zinc finger protein, Red1, to form the MTREC core complex, which is involved in heterochromatic silencing and degradation of meiotic RNAs, CUTs, and unspliced transcripts (Lee et al. 2013; Egan et al. 2014; Zhou et al. 2015). MTREC also interacts with the CBCA complex and the exosome, and the Red1 subunit shares homology with ZFC3H1 (Lee et al. 2013; Zhou et al. 2015), possibly indicating that it is the fission yeast counterpart to the human PAXT complex. Importantly, NEXT, PAXT, and MTREC complexes lack 3' polyadenylation activity, suggesting that their RNA-binding and helicase activities are sufficient to generate $3^{\prime}$ ssRNA that is long enough to engage the exosome.

\section{Mtr4/AIM interactions for selective RNA decay}

rRNAs are derived from two transcripts in S. cerevisiae: one that codes for the 18S, 5.8S, and 25S rRNAs and another that codes for the $5 \mathrm{~S}$ rRNA (Fig. 4A,B; for review, see Henras et al. 2014). A set of proteins known as the processome dynamically associates with the pre-rRNA cotranscriptionally to direct endonucleolytic and exonucleolytic RNA processing in addition to chaperoning ribosomal proteins within the RNP (for review, see Woolford and Baserga 2013). By aptamer tagging and affinity-purifying rRNAs of different lengths, a recent study dissected the order in which processome subcomplexes associate with and dissociate from the pre-rRNA that encompasses the SSU (Chaker-Margot et al. 2015), although molecular details underlying these interactions remain elusive.

Another recent study addressing rRNA processing uncovered a conserved motif (arch-interacting motif [AIM]) in processome proteins Utp18 and Nop53 that interacts with the arch of Mtr4 to recruit the exosome (Thoms et al. 2015). They found that interaction of the Mtr4 arch with this motif in Utp18, a subunit of the early associating processome subcomplex UtpB, enables removal of the $5^{\prime}$ externally transcribed spacer (ETS), while interaction with Nop53, a later associating processome factor, enables processing of the 5.8S RNA (Fig. 4C,D). A cryoEM-derived model of the SSU processome at 5.1-A resolution revealed that the $\beta$-propeller domain of Utp 18 resides on the periphery of the complex $\sim 75 \AA$ from the $\mathrm{A}_{0}$ site of 


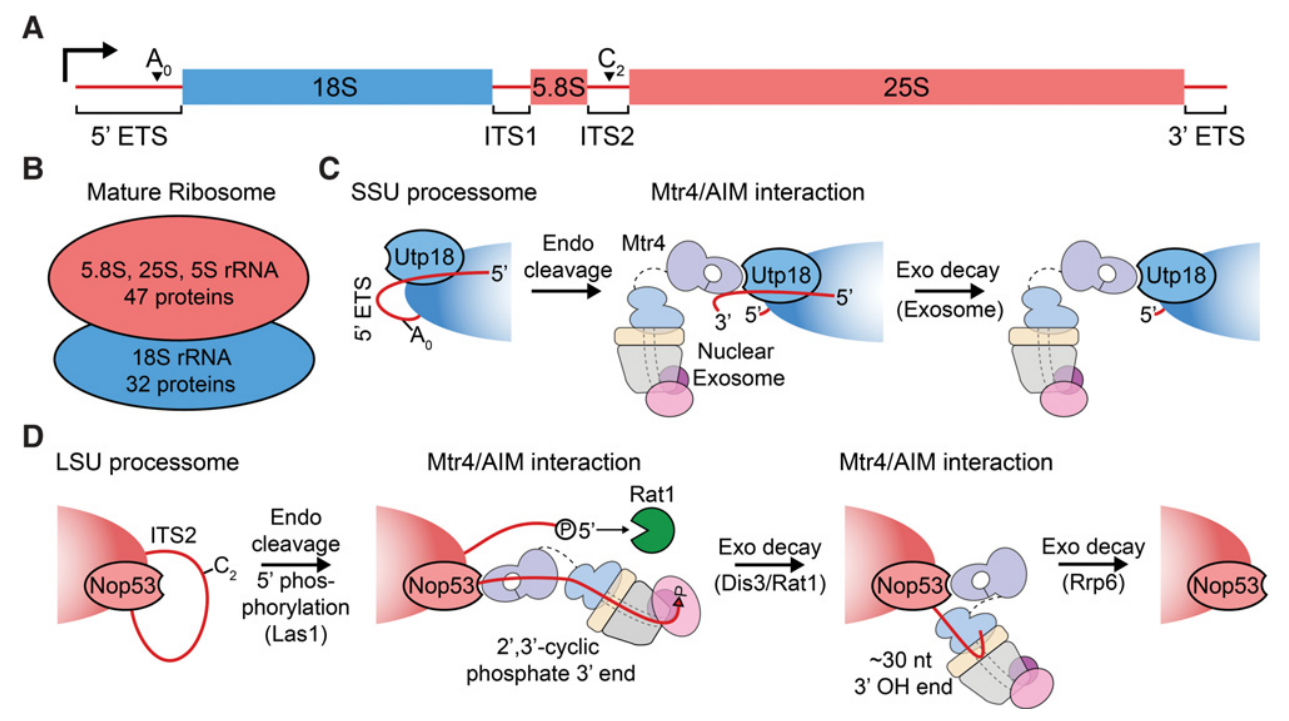

Figure 4. AIM-Arch interactions recruit the exosome for rRNA processing $(A)$ Schematic for the S. cerevisiae 7-kb pre-rRNA molecule. Regions of the RNA contained within the mature ribosome are shown as boxes, and spacers are shown as lines. The direction of transcription is shown with an arrow, and $A_{0}$ and $C_{2}$ endonucleolytic cleavage sites are indicated. (B) Schematic for a mature ribosome. (C) A Utp18 ${ }_{\text {AIM }}-$ Mtr4 $_{\text {Arch }}$ interaction recruits the exosome for $5^{\prime}$ externally transcribed spacer (ETS) removal after endonucleolytic cleavage at the $\mathrm{A}_{0}$ site. $(D) \mathrm{A}$ Nop53 $\mathrm{AIM}^{-M t r} 4_{\text {Arch }}$ interaction recruits the exosome for $5.8 \mathrm{~S}$ rRNA processing after Las 1 cleavage at the $\mathrm{C}_{2}$ site.

the 5' ETS, although its N-terminal 250 amino acids (which contain the AIM) could not be modeled (Fig. 4C; Chaker-Margot et al. 2016). Mutation of the AIM on Utp18 or Nop53 resulted in accumulation of unprocessed precursors for their respective substrates. Interestingly, other proteins such as Air2 and Sqs1 can interact with the Mtr4 arch in a region similar to Nop53/Utp18, suggesting that hierarchical competition for the arch may contribute to RNA decay in the nucleus (Losh and van Hoof 2015; Thoms et al. 2015).

\section{$3^{\prime}$ end chemistry and RNA fate}

Dis3- or Rrp6-mediated degradation of model substrates by exosomes containing Dis3 and Rrp6 appears stochastic in vitro; however, this seems an unlikely strategy for selective targeting of RNA for processing or degradation in vivo. While nuclear cofactor complexes can influence RNA fate as discussed, recent studies suggested that the chemical structure of the $3^{\prime}$ end might influence the fate of a particular RNA. For example, Rrp6 from humans and $S$. cerevisiae lacks activity on synthetic RNA containing a $3^{\prime}$ phosphate, while Dis3 family enzymes readily degrade these RNAs (Burkard and Butler 2000; Tomecki et al. 2010; Lubas et al. 2013; Domanski et al. 2016; Zinder et al. 2016). While RNA with $3^{\prime}$ phosphate may not be prevalent in vivo, $3^{\prime}$ phosphate ends can result from random breaks elicited by damaging agents or by purposeful endonucleolytic cleavage. Examples of the latter include $2^{\prime}, 3^{\prime}$-cyclic phosphate modification, the product of maturation reactions for a number of RNAs, including tRNA introns, U6 snRNA, and rRNA precursors (Knapp et al. 1979; Lund and Dahlberg 1992; Gasse et al. 2015). Al- though untested, structural studies suggest that Rrp44, but not Rrp6, could degrade RNAs with $2^{\prime}, 3^{\prime}$-cyclic phosphate $3^{\prime}$ ends (Zinder et al. 2016).

For U6 RNA, Mpn1 (also called Usb1) generates a 2', $3^{\prime}$ cyclic phosphate at the $3^{\prime}$ end as a product of its exonuclease activity, and U6 is polyadenylated and rapidly degraded in a $\Delta m p n 1$ S. pombe strain (Shchepachev et al. 2012, 2015). This suggests that a $2^{\prime}, 3^{\prime}$-cyclic phosphate stabilizes U6 by preventing decay by Rrp6 or polyadenylation by TRAMP. Indeed, a transcriptome-wide survey of $2^{\prime}, 3^{\prime}$-cyclic phosphate RNAs revealed that U6 is by far the most abundant RNA with this chemical signature in HeLa cells, although this approach may have missed other RNAs that are targeted for rapid degradation (Schutz et al. 2010).

To generate the 7S rRNA /5.8S rRNA with a 3 ' extension), the Las1 endonuclease component of the Las1 complex cleaves the rRNA precursor molecule at the $\mathrm{C}_{2}$ site of internally transcribed spacer 2 (ITS2) (Fig. 4A; Gasse et al. 2015), resulting in a $2^{\prime}, 3^{\prime}$-cyclic phosphate at the $3^{\prime}$ end of the $7 \mathrm{~S}$ rRNA and a $5^{\prime} \mathrm{OH}$ on the other fragment. While the latter RNA is $5^{\prime}$ phosphorylated by the Las 1 complex to enable processing by the nuclear $5^{\prime}$-to- $3^{\prime}$ exonuclease Rat1/Xrn2 (Fig. 4D), the $2^{\prime}, 3^{\prime}$-cyclic phosphate end is an intermediate prior to processive $3^{\prime}$-to- $5^{\prime}$ processing by Dis3 (Fig. 4D). This produces the 5.8S rRNA plus 30 nt at the $3^{\prime}$ end, the approximate length required to span the Exo9 central channel. This overhang is subsequently removed by Rrp6 (Fig. 4D; Briggs et al. 1998; Allmang et al. 1999a). While this and other $2^{\prime}, 3^{\prime}$-cyclic phosphate $3^{\prime}$ ends may be resolved by phosphodiesterases prior to processing or degradation, it remains possible that $3^{\prime}$-modified RNAs could be substrates of Dis3 and the nuclear RNA exosome. 


\section{Conclusions and future challenges}

The RNA exosome and its cofactors provide a versatile platform for targeting a wide variety of RNA substrates for processing and/or degradation in the nucleus and cytoplasm. Although the exosome was discovered two decades ago, it seems that we are just beginning to piece together its complexity. Armed with various cofactors that presumably recruit and/or localize the exosome to different subcellular compartments or complexes, it remains unclear how particular complexes compete with one another to promote these functions. With respect to structural studies, it remains a significant challenge to capture intermediates during recruitment and/or degradation, as most factors require a $3^{\prime}$ end for activity. For instance, TRAMPmediated decay includes at least four enzymes that bind an RNA 3' end: a 3' nontemplated poly(A) polymerase, a 3'-to-5' RNA helicase, and two 3'-to-5'-directed exoribonucleases (Fig. 2). Perhaps most relevant is the need to uncover regulatory mechanisms that mark a particular RNA for degradation. In this context, we are again reminded of conceptual parallels between the RNA exosome and ubiquitin-proteasome pathways, beyond those noted previously. While the proteasome was long viewed as a trash can for protein degradation, the discovery of a vast network of regulated processes involving ubiquitin E2-conjugating enzymes, E3 ligases, and shuttling factors that deliver substrates to the proteasome made it clear that protein degradation was not a passive process but an active and highly regulated quality control pathway. Many cofactors for the exosome have been uncovered; however, regulatory signals underlying their activities and/or specificities will remain an area of interest for years to come.

\section{Acknowledgments}

We acknowledge members of the Lima and Klinge laboratories for their helpful discussions, and colleagues whose work we could not cite due to space limitations. This research was supported in part by National Institutes of Health/National Institute of General Medical Sciences grants R01GM079196 (to C.D.L.), R35GM118080 (to C.D.L.), and P30 CA008748 (National Institutes of Health National Cancer Institute-Cancer Center support grant). C.D.L. is an Investigator of the Howard Hughes Medical Institute The content is solely the responsibility of the authors and does not represent the official views of the National Institutes of Health.

\section{References}

Allmang C, Kufel J, Chanfreau G, Mitchell P, Petfalski E, Tollervey D. 1999a. Functions of the exosome in rRNA, snoRNA and snRNA synthesis. EMBO J 18: 5399-5410.

Allmang C, Petfalski E, Podtelejnikov A, Mann M, Tollervey D, Mitchell P. 1999b. The yeast exosome and human PM-Scl are related complexes of $3^{\prime}-5^{\prime}$ exonucleases. Genes Dev 13: 2148-2158.

Aly HH, Suzuki J, Watashi K, Chayama K, Hoshino S-I, Hijikata M, Kato T, Wakita T. 2016. RNA exosome complex regulates stability of the hepatitis B virus X-mRNA transcript in a non- stop-mediated (NSD) RNA quality control mechanism. J Biol Chem 291: 15958-15974.

Andersen PR, Domanski M, Kristiansen MS, Storvall H, Ntini E, Verheggen C, Schein A, Bunkenborg J, Poser I, Hallais M, et al. 2013. The human cap-binding complex is functionally connected to the nuclear RNA exosome. Nat Struct Mol Biol 20: $1367-1376$.

Anderson JSJ, Parker R. 1998. The $3^{\prime}$ to $5^{\prime}$ degradation of yeast mRNAs is a general mechanism for mRNA turnover that requires the SKI2 DEVH box protein and $3^{\prime}$ to $5^{\prime}$ exonucleases of the exosome complex. EMBO J 17: 1497-1506.

Araki Y, Takahashi S, Kobayashi T, Kajiho H, Hoshino S, Katada T. 2001. Ski7p G protein interacts with the exosome and the Ski complex for $3^{\prime}$ to $5^{\prime}$ mRNA decay in yeast. $E M B O / 20$ : 4684-4693.

Assenholt J, Mouaikel J, Andersen KR, Brodersen DE, Libri D, Jensen TH. 2008. Exonucleolysis is required for nuclear mRNA quality control in yeast THO mutants. RNA 14: 2305-2313.

Bonneau F, Basquin J, Ebert J, Lorentzen E, Conti E. 2009. The yeast exosome functions as a macromolecular cage to channel RNA substrates for degradation. Cell 139: 547-559.

Briggs MW, Burkard KT, Butler JS. 1998. Rrp6p, the yeast homologue of the human PM-Scl 100-kDa autoantigen, is essential for efficient 5.8 S rRNA $3^{\prime}$ end formation. I Biol Chem 273: 13255-13263.

Brouwer R, Allmang C, Raijmakers R, van Aarssen Y, Egberts WV, Petfalski E, van Venrooij WJ, Tollervey D, Pruijn GJM. 2000. Three novel components of the human exosome. I Biol Chem 276: 6177-6184.

Brown JT, Bai X, Johnson AW. 2000. The yeast antiviral proteins Ski2p, Ski3p, and Ski8p exist as a complex in vivo. RNA 6: 449-457.

Burkard KT, Butler JS. 2000. A nuclear 3'-5' exonuclease involved in mRNA degradation interacts with Poly(A) polymerase and the hnRNA protein Npl3p. Mol Cell Biol 20: 604-616.

Castaño IB, Heath-Pagliuso S, Sadoff BU, Fitzhugh DJ, Christman MF. 1996. A novel family of TRF (DNA topoisomerase I-related function) genes required for proper nuclear segregation. $\mathrm{Nu}$ cleic Acids Res 24: 2404-2410.

Chaker-Margot M, Hunziker M, Barandun J, Dill BD, Klinge S. 2015. Stage-specific assembly events of the 6-MDa small-subunit processome initiate eukaryotic ribosome biogenesis. Nat Struct Mol Biol 22: 920-923.

Chaker-Margot M, Barandun J, Hunziker M, Klinge S. 2016. Architecture of the yeast small subunit processome. Science 355: eaal1880.

Chapman MA, Lawrence MS, Keats JJ, Cibulskis K, Sougnez C, Schinzel AC, Harview CL, Brunet J-P, Ahmann GJ, Adli M, et al. 2011. Initial genome sequencing and analysis of multiple myeloma. Nature 471: 467-472.

Chekanova JA, Gregory BD, Reverdatto SV, Chen H, Kumar R, Hooker T, Yazaki J, Li P, Skiba N, Peng Q, et al. 2007. Genome-wide high-resolution mapping of exosome substrates reveals hidden features in the Arabidopsis transcriptome. Cell 131: 1340-1353.

Chen CY, Gherzi R, Ong SE, Chan EL, Raijmakers R, Pruijn GJ, Stoecklin G, Moroni C, Mann M, Karin M. 2001. AU binding proteins recruit the exosome to degrade ARE-containing mRNAs. Cell 107: 451-464.

Costello JL, Stead JA, Feigenbutz M, Jones RM, Mitchell P. 2011. The C-terminal region of the exosome-associated protein Rrp47 is specifically required for box C/D small nucleolar RNA 3'-maturation. J Biol Chem 286: 4535-4543.

Domanski M, Upla P, Rice WJ, Molloy KR, Ketaren NE, Stokes DL, Jensen TH, Rout MP, LaCava J. 2016. Purification and 
analysis of endogenous human RNA exosome complexes. RNA 22: 1467-1475.

Drazkowska K, Tomecki R, Stodus K, Kowalska K, CzarnockiCieciura M, Dziembowski A. 2013. The RNA exosome complex central channel controls both exonuclease and endonuclease Dis3 activities in vivo and in vitro. Nucleic Acids Res 41: 3845-3858.

Dziembowski A, Lorentzen E, Conti E, Séraphin B. 2007. A single subunit, Dis3, is essentially responsible for yeast exosome core activity. Nat Struct Mol Biol 14: 15-22.

Egan ED, Braun CR, Gygi SP, Moazed D. 2014. Post-transcriptional regulation of meiotic genes by a nuclear RNA silencing complex. RNA 20: 867-881.

Eser S, Schnieke A, Schneider G, Saur D. 2014. Oncogenic KRAS signalling in pancreatic cancer. Br J Cancer 111: 817-822.

Fabre A, Badens C. 2014. Human Mendelian diseases related to abnormalities of the RNA exosome or its cofactors. Intractable Rare Dis Res 3: 8-11.

Falk S, Weir JR, Hentschel J, Reichelt P, Bonneau F, Conti E. 2014. The molecular architecture of the TRAMP complex reveals the organizationand interplay of its two catalytic activities. Mol Cell 55: 856-867.

Falk S, Finogenova K, Melko M, Benda C, Lykke-Andersen S, Jensen TH, Conti E. 2016. Structure of the RBM7-ZCCHC8 core of the NEXT complex reveals connections to splicing factors. Nat Commun 7: 13573.

Feigenbutz M, Garland W, Turner M, Mitchell P. 2013. The exosome cofactor Rrp47 is critical for the stability and normal expression of its associated exoribonuclease Rrp6 in Saccharomyces cerevisiae. PLoS One 8: e80752.

Garland W, Feigenbutz M, Turner M, Mitchell P. 2013. Rrp47 functions in RNA surveillance and stable RNA processing when divorced from the exoribonuclease and exosome-binding domains of Rrp6. RNA 19: 1659-1668.

Gasse L, Flemming D, Hurt E. 2015. Coordinated ribosomal ITS2 RNA processing by the Las 1 complex integrating endonuclease, polynucleotide kinase, and exonuclease activities. Mol Cell 60: 808-815.

Gudipati RK, Xu Z, Lebreton A, Séraphin B, Steinmetz LM, Jacquier A, Libri D. 2012. Extensive degradation of RNA precursors by the exosome in wild-type cells. Mol Cell 48: 409-421.

Halbach F, Rode M, Conti E. 2012. The crystal structure of S. cerevisiae Ski2, a DExH helicase associated with the cytoplasmic functions of the exosome. RNA 18: 124-134.

Halbach F, Reichelt P, Rode M, Conti E. 2013. The yeast Ski complex: crystal structure and RNA channeling to the exosome complex. Cell 154: 814-826.

Hamill S, Wolin SL, Reinisch KM. 2010. Structure and function of the polymerase core of TRAMP, a RNA surveillance complex. Proc Natl Acad Sci 107: 15045-15050.

Han J, van Hoof A. 2016. The RNA exosome channeling and direct access conformations have distinct in vivo functions. Cell Rep 16: 3348-3358.

Harigaya Y, Tanaka H, Yamanaka S, Tanaka K, Watanabe Y, Tsutsumi C, Chikashige Y, Hiraoka Y, Yamashita A, Yamamoto M. 2006. Selective elimination of messenger RNA prevents an incidence of untimely meiosis. Nature 442: 45-50.

Henras AK, Plisson-Chastang C, O'Donohue M-F, Chakraborty A, Gleizes P-E. 2014. An overview of pre-ribosomal RNA processing in eukaryotes. Wiley Interdiscip Rev RNA 6: 225-242.

Hoskins JW, Ibrahim A, Emmanuel MA, Manmiller SM, Wu Y, O'Neill M, Jia J, Collins I, Zhang M, Thomas JV, et al. 2016. Functional characterization of a chr13q22.1 pancreatic cancer risk locus reveals long-range interaction and allele-specific ef- fects on DIS3 expression. Hum Mol Genet. doi:10.1093/hmg/ ddw300

Jackson RN, Klauer AA, Hintze BJ, Robinson H, van Hoof A, Johnson SJ. 2010. The crystal structure of Mtr4 reveals a novel arch domain required for rRNA processing. EMBO J 29: 2205-2216.

Jackson RA, Wu JS, Chen ES. 2016. C1D family proteins in coordinating RNA processing, chromosome condensation and DNA damage response. Cell Div 11: 2.

Januszyk K, Lima CD. 2014. The eukaryotic RNA exosome. Curr Opin Struct Biol 24: 132-140.

Kadaba S, Krueger A, Trice T, Krecic AM, Hinnebusch AG, Anderson J. 2004. Nuclear surveillance and degradation of hypomodified initiator tRNAMet in S. cerevisiae. Genes Dev 18: 1227-1240.

Kalisiak K, Kulinski TM, Tomecki R, Cysewski D, Pietras Z, Chlebowski A, Kowalska K, Dziembowski A. 2016. A short splicing isoform of HBS1L links the cytoplasmic exosome and SKI complexes in humans. Nucleic Acids Res. doi:10.1093/nar/gkw862

Kilchert C, Wittmann S, Vasiljeva L. 2016. The regulation and functions of the nuclear RNA exosome complex. Nat Rev Mol Cell Biol 17: 227-239.

Kim K, Heo D-H, Kim I, Suh J-Y, Kim M. 2016. Exosome cofactors connect transcription termination to RNA processing by guiding terminated transcripts to the appropriate exonuclease within the nuclear exosome. J Biol Chem 291: 13229-13242.

Knapp G, Ogden RC, Peebles CL, Abelson J. 1979. Splicing of yeast tRNA precursors: structure of the reaction intermediates. Cell 18: 37-45.

Kowalinski E, Schuller A, Green R, Conti E. 2015. Saccharomyces cerevisiae Ski7 is a GTP-binding protein adopting the characteristic conformation of active translational GTPases. Structure 23: 1336-1343.

Kowalinski E, Kögel A, Ebert J, Reichelt P, Stegmann E, Habermann B, Conti E. 2016. Structure of a cytoplasmic 11-subunit RNA exosome complex. Mol Cell 63: 125-134.

Łabno A, Tomecki R, Dziembowski A. 2016. Cytoplasmic RNA decay pathways-enzymes and mechanisms. Biochim Biophys Acta 1863: 3125-3147.

LaCava J, Houseley J, Saveanu C, Petfalski E, Thompson E, Jacquier A, Tollervey D. 2005. RNA degradation by the exosome is promoted by a nuclear polyadenylation complex. Cell 121: 713-724.

Lebreton A, Tomecki R, Dziembowski A, Séraphin B. 2008. Endonucleolytic RNA cleavage by a eukaryotic exosome. Nature 456: 993-996.

Lee NN, Chalamcharla VR, Reyes-Turcu F, Mehta S, Zofall M, Balachandran V, Dhakshnamoorthy J, Taneja N, Yamanaka S, Zhou M, et al. 2013. Mtr4-like protein coordinates nuclear RNA processing for heterochromatin assembly and for telomere maintenance. Cell 155: 1061-1074.

Liu Q, Greimann JC, Lima CD. 2006. Reconstitution, activities, and structure of the eukaryotic RNA exosome. Cell 127: 1223-1237.

Liu J-J, Bratkowski MA, Liu X, Niu C-Y, Ke A, Wang H-W. 2014. Visualization of distinct substrate-recruitment pathways in the yeast exosome by EM. Nat Struct Mol Biol 21: 95-102.

Liu J-J, Niu C-Y, Wu Y, Tan D, Wang Y, Ye M-D, Liu Y, Zhao W, Zhou K, Liu Q-S, et al. 2016. CryoEM structure of yeast cytoplasmic exosome complex. Cell Res 26: 822-837.

Lohr JG, Stojanov P, Carter SL, Cruz-Gordillo P, Lawrence MS, Auclair D, Sougnez C, Knoechel B, Gould J, Saksena G, et al. 2014. Widespread genetic heterogeneity in multiple myeloma: implications for targeted therapy. Cancer Cell 25: 91-101. 
Losh JS, van Hoof A. 2015. Gateway arch to the RNA exosome. Cell 162: 940-941.

Losh JS, King AK, Bakelar J, Taylor L, Loomis J, Rosenzweig JA, Johnson SI, van Hoof A. 2015. Interaction between the RNA-dependent ATPase and poly(A) polymerase subunits of the TRAMP complex is mediated by short peptides and important for snoRNA processing. Nucleic Acids Res 43: 1848-1858.

Lubas M, Christensen MS, Kristiansen MS, Domanski M, Falkenby LG, Lykke-Andersen S, Andersen JS, Dziembowski A, Jensen TH. 2011. Interaction profiling identifies the human nuclear exosome targeting complex. Mol Cell 43: 624-637.

Lubas M, Damgaard CK, Tomecki R, Cysewski D, Jensen TH, Dziembowski A. 2013. Exonuclease hDIS3L2 specifies an exosome-independent $3^{\prime}-5^{\prime}$ degradation pathway of human cytoplasmic mRNA. EMBO $J$ 32: 1855-1868.

Lund E, Dahlberg JE. 1992. Cyclic 2',3'-phosphates and nontemplated nucleotides at the $3^{\prime}$ end of spliceosomal U6 small nuclear RNAs. Science 255: 327-330.

Macias S, Cordiner RA, Cáceres JF. 2013. Cellular functions of the microprocessor. Biochem Soc Trans 41: 838-843.

Macias S, Cordiner RA, Gautier P, Plass M, Cáceres JF. 2015. DGCR8 acts as an adaptor for the exosome complex to degrade double-stranded structured RNAs. Mol Cell 60: 873-885.

Makino DL, Baumgärtner M, Conti E. 2013. Crystal structure of an RNA-bound 11-subunit eukaryotic exosome complex. $\mathrm{Na}$ ture 495: 70-75.

Makino DL, Schuch B, Stegmann E, Baumgärtner M, Basquin C, Conti E. 2015. RNA degradation paths in a 12-subunit nuclear exosome complex. Nature 524: 54-58.

McIver SC, Kang Y-A, DeVilbiss AW, O'Driscoll CA, Ouellette JN, Pope NJ, Camprecios G, Chang C-J, Yang D, Bouhassira EE, et al. 2014. The exosome complex establishes a barricade to erythroid maturation. Blood 124: 2285-2297.

McIver SC, Katsumura KR, Davids E, Liu P, Kang Y-A, Yang D, Bresnick EH. 2016. Exosome complex orchestrates developmental signaling to balance proliferation and differentiation during erythropoiesis. Elife 5: 5399.

Meola N, Domanski M, Karadoulama E, Chen Y, Gentil C, Pultz D, Vitting-Seerup K, Lykke-Andersen S, Andersen JS, Sandelin A, et al. 2016. Identification of a nuclear exosome decay pathway for processed transcripts. Mol Cell 64: 520-533.

Mistry DS, Chen Y, Sen GL. 2012. Progenitor function in self-renewing human epidermis is maintained by the exosome. Cell Stem Cell 11: 127-135.

Mitchell P. 2010. Rrp47 and the function of the Sas10/C1D domain. Biochem Soc Trans 38: 1088-1092.

Mitchell P, Petfalski E, Shevchenko A, Mann M, Tollervey D. 1997. The exosome: a conserved eukaryotic RNA processing complex containing multiple $3^{\prime}-5^{\prime}$ exoribonucleases. Cell 91: 457-466.

Molleston JM, Sabin LR, Moy RH, Menghani SV, Rausch K, Gordesky-Gold B, Hopkins KC, Zhou R, Jensen TH, Wilusz JE, et al. 2016. A conserved virus-induced cytoplasmic TRAMPlike complex recruits the exosome to target viral RNA for degradation. Genes Dev 30: 1658-1670.

Mukherjee K, Gardin J, Futcher B, Leatherwood J. 2016. Relative contributions of the structural and catalytic roles of Rrp6 in exosomal degradation of individual mRNAs. RNA 22: 1311-1319.

Nguyen D, Grenier St-Sauveur V, Bergeron D, Dupuis-Sandoval F, Scott MS, Bachand F. 2015a. A polyadenylation-dependent 3' end maturation pathway is required for the synthesis of the human telomerase RNA. Cell Rep 13: 2244-2257.
Nguyen TA, Jo MH, Choi Y-G, Park J, Kwon SC, Hohng S, Kim VN, Woo J-S. 2015b. Functional anatomy of the human microprocessor. Cell 161: 1374-1387.

Ohkura H, Adachi Y, Kinoshita N, Niwa O, Toda T, Yanagida M. 1988. Cold-sensitive and caffeine-supersensitive mutants of the Schizosaccharomyces pombe dis genes implicated in sister chromatid separation during mitosis. EMBO I 7: 1465-1473.

Pefanis E, Wang J, Rothschild G, Lim J, Chao J, Rabadan R, Economides AN, Basu U. 2014. Noncoding RNA transcription targets AID to divergently transcribed loci in B cells. Nature 514: 389-393.

Preker P, Nielsen J, Kammler S, Lykke-Andersen S, Christensen MS, Mapendano CK, Schierup MH, Jensen TH. 2008. RNA exosome depletion reveals transcription upstream of active human promoters. Science 322: 1851-1854.

Ridley SP, Sommer SS, Wickner RB. 1984. Superkiller mutations in Saccharomyces cerevisiae suppress exclusion of M2 double-stranded RNA by L-A-HN and confer cold sensitivity in the presence of M and L-A-HN. Mol Cell Biol 4: 761-770.

Robinson SR, Oliver AW, Chevassut TJ, Newbury SF. 2015. The $3^{\prime}$ to $5^{\prime}$ exoribonuclease DIS3: from structure and mechanisms to biological functions and role in human disease. Biomolecules 5: 1515-1539.

Schaeffer D, Tsanova B, Barbas A, Reis FP, Dastidar EG, SanchezRotunno M, Arraiano CM, van Hoof A. 2009. The exosome contains domains with specific endoribonuclease, exoribonuclease and cytoplasmic mRNA decay activities. Nat Struct Mol Biol 16: 56-62.

Schilders G. 2005. MPP6 is an exosome-associated RNA-binding protein involved in 5.8S rRNA maturation. Nucleic Acids Res 33: 6795-6804.

Schmidt C, Kowalinski E, Shanmuganathan V, Defenouillere Q, Braunger K, Heuer A, Pech M, Namane A, Berninghausen 0, Fromont-Racine M, et al. 2016. The cryo-EM structure of a ribosome-Ski2-Ski3-Ski8 helicase complex. Science 354: 1431-1433.

Schneider C, Leung E, Brown J, Tollervey D. 2008. The N-terminal PIN domain of the exosome subunit Rrp44 harbors endonuclease activity and tethers Rrp44 to the yeast core exosome. Nucleic Acids Res 37: 1127-1140.

Schneider C, Kudla G, Wlotzka W, Tuck A, Tollervey D. 2012. Transcriptome-wide analysis of exosome targets. Mol Cell 48: 422-433.

Schuch B, Feigenbutz M, Makino DL, Falk S, Basquin C, Mitchell P, Conti E. 2014. The exosome-binding factors Rrp6 and Rrp47 form a composite surface for recruiting the Mtr4 helicase. EMBO J 33: 2829-2846.

Schutz K, Hesselberth JR, Fields S. 2010. Capture and sequence analysis of RNAs with terminal $2^{\prime}, 3^{\prime}$-cyclic phosphates. RNA 16: 621-631.

Segalla S, Pivetti S, Todoerti K, Chudzik MA, Giuliani EC, Lazzaro F, Volta V, Lazarevic D, Musco G, Muzi-Falconi M, et al. 2015. The ribonuclease DIS3 promotes let-7 miRNA maturation by degrading the pluripotency factor LIN28B mRNA. Nucleic Acids Res 43: 5182-5193.

Shchepachev V, Wischnewski H, Missiaglia E, Soneson C, Azzalin CM. 2012. Mpn1, mutated in poikiloderma with neutropenia protein 1 , is a conserved $3^{\prime}$-to- $5^{\prime}$ RNA exonuclease processing U6 small nuclear RNA. Cell Rep 2: 855-865.

Shchepachev V, Wischnewski H, Soneson C, Arnold AW, Azzalin CM. 2015. Human Mpn1 promotes post-transcriptional processing and stability of U6atac. FEBS Lett 589: 2417-2423.

Shi Y, Pellarin R, Fridy PC, Fernandez-Martinez J, Thompson MK, Li Y, Wang QJ, Sali A, Rout MP, Chait BT. 2015. A 
strategy for dissecting the architectures of native macromolecular assemblies. Nat Methods 12: 1135-1138.

Shukla S, Schmidt JC, Goldfarb KC, Cech TR, Parker R. 2016. Inhibition of telomerase RNA decay rescues telomerase deficiency caused by dyskerin or PARN defects. Nat Struct Mol Biol 23: 286-292.

Snee MJ, Wilson WC, Zhu Y, Chen S-Y, Wilson BA, Kseib C, O'Neal J, Mahajan N, Tomasson MH, Arur S, et al. 2016. Collaborative control of cell cycle progression by the RNA exonuclease Dis3 and Ras is conserved across species. Genetics 203: 749-762.

Staals RHJ, Pruijn GJM. 2010. The human exosome and disease. Adv Exp Med Biol 702: 132-142.

Staals RHJ, Bronkhorst AW, Schilders G, Slomovic S, Schuster G, Heck AJR, Raijmakers R, Pruijn GJM. 2010. Dis3-like 1: a novel exoribonuclease associated with the human exosome. EMBO I 29: 2358-2367.

Targoff IN, Reichlin M. 1985. Nucleolar localization of the PMScl antigen. Arthritis Rheum 28: 226-230.

Taylor LL, Jackson RN, Rexhepaj M, King AK, Lott LK, van Hoof A, Johnson SJ. 2014. The Mtr4 ratchet helix and arch domain both function to promote RNA unwinding. Nucleic Acids Res 42: 13861-13872.

Thoms M, Thomson E, Baßler J, Gnädig M, Griesel S, Hurt E. 2015. The exosome is recruited to RNA substrates through specific adaptor proteins. Cell 162: 1029-1038.

Toh-E A, Guerry P, Wickner RB. 1978. Chromosomal superkiller mutants of Saccharomyces cerevisiae. I Bacteriology 136: 1002-1007.

Tomecki R, Kristiansen MS, Lykke-Andersen SOR, Chlebowski A, Larsen KM, Szczesny RJ, Drazkowska K, Pastula A, Andersen IS, Stepien PP, et al. 2010. The human core exosome interacts with differentially localized processive RNases: hDIS3 and hDIS3L. EMBO T 29: 2342-2357.

Tomecki R, Drazkowska K, Kucinski I, Stodus K, Szczesny RJ, Gruchota J, Owczarek EP, Kalisiak K, Dziembowski A. 2014. Multiple myeloma-associated hDIS3 mutations cause perturbations in cellular RNA metabolism and suggest hDIS3 PIN domain as a potential drug target. Nucleic Acids Res 42: 1270-1290.

Tseng C-K, Wang H-F, Burns AM, Schroeder MR, Gaspari M, Baumann P. 2015. Human telomerase RNA processing and quality control. Cell Rep 13: 2232-2243.

Vanacova S, Wolf J, Martin G, Blank D, Dettwiler S, Friedlein A, Langen H, Keith G, Keller W. 2005. A new yeast poly(A) poly- merase complex involved in RNA quality control. PLoS Biol 3: e189.

van Hoof A, Parker R. 1999. The exosome: a proteasome for RNA? Cell 99: 347-350.

van Hoof A, Staples RR, Baker RE, Parker R. 2000. Function of the Ski4p (Cs14p) and Ski7p proteins in $3^{\prime}$-to-5' degradation of mRNA. Mol Cell Biol 20: 8230-8243.

van Hoof A, Frischmeyer PA, Dietz HC, Parker R. 2002. Exosomemediated recognition and degradation of $\mathrm{mRNAs}$ lacking a termination codon. Science 295: 2262-2264.

Walker BA, Wardell CP, Melchor L, Hulkki S, Potter NE, Johnson DC, Fenwick K, Kozarewa I, Gonzalez D, Lord CI, et al. 2012. Intraclonal heterogeneity and distinct molecular mechanisms characterize the development of $\mathrm{t}(4 ; 14)$ and $\mathrm{t}(11 ; 14)$ myeloma. Blood 120: 1077-1086.

Wang L, Lewis MS, Johnson AW. 2005. Domain interactions within the Ski2/3/8 complex and between the Ski complex and Ski7p. RNA 11: 1291-1302.

Wasmuth EV, Lima CD. 2012. Exo- and endoribonucleolytic activities of yeast cytoplasmic and nuclear RNA exosomes are dependent on the noncatalytic core and central channel. Mol Cell 48: 133-144.

Wasmuth EV, Lima CD. 2017. The Rrp6 C-terminal domain binds RNA and activates the nuclear RNA exosome. Nucleic Acids Res 45: 846-860.

Wasmuth EV, Januszyk K, Lima CD. 2014. Structure of an Rrp6RNA exosome complex bound to poly(A) RNA. Nature 511: 435-439.

Weir JR, Bonneau F, Hentschel J, Conti E. 2010. Structural analysis reveals the characteristic features of Mtr4, a DExH helicase involved in nuclear RNA processing and surveillance. Proc Nat1 Acad Sci 107: 12139-12144.

Woolford JL, Baserga SJ. 2013. Ribosome biogenesis in the yeast Saccharomyces cerevisiae. Genetics 195: 643-681.

Wyers F, Rougemaille M, Badis G, Rousselle J-C, Dufour M-E, Boulay J, Régnault B, Devaux F, Namane A, Séraphin B, et al. 2005. Cryptic pol II transcripts are degraded by a nuclear quality control pathway involving a new poly(A) polymerase. Cell 121: 725-737.

Zhou Y, Zhu J, Schermann GEZ, Ohle C, Bendrin K, Sugioka-Sugiyama R, Sugiyama T, Fischer TAS. 2015. The fission yeast MTREC complex targets CUTs and unspliced pre-mRNAs to the nuclear exosome. Nat Commun 6: 1-11.

Zinder JC, Wasmuth EV, Lima CD. 2016. Nuclear RNA exosome at $3.1 \AA$ A reveals substrate specificities, RNA paths, and allosteric inhibition of Rrp44/Dis3. Mol Cell 64: 734-745. 


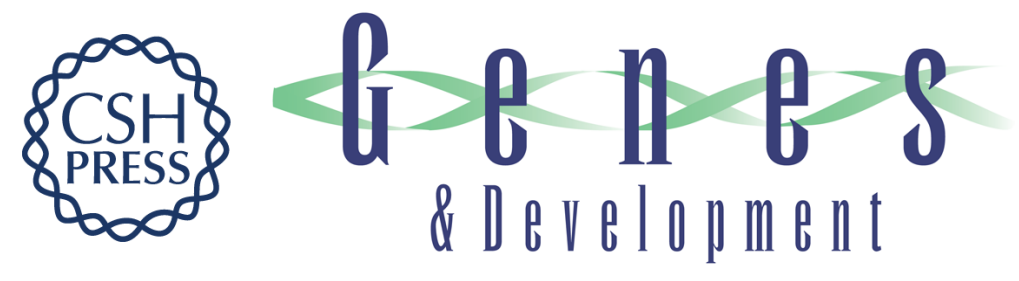

\section{Targeting RNA for processing or destruction by the eukaryotic RNA exosome and its cofactors}

John C. Zinder and Christopher D. Lima

Genes Dev. 2017, 31:

Access the most recent version at doi:10.1101/gad.294769.116

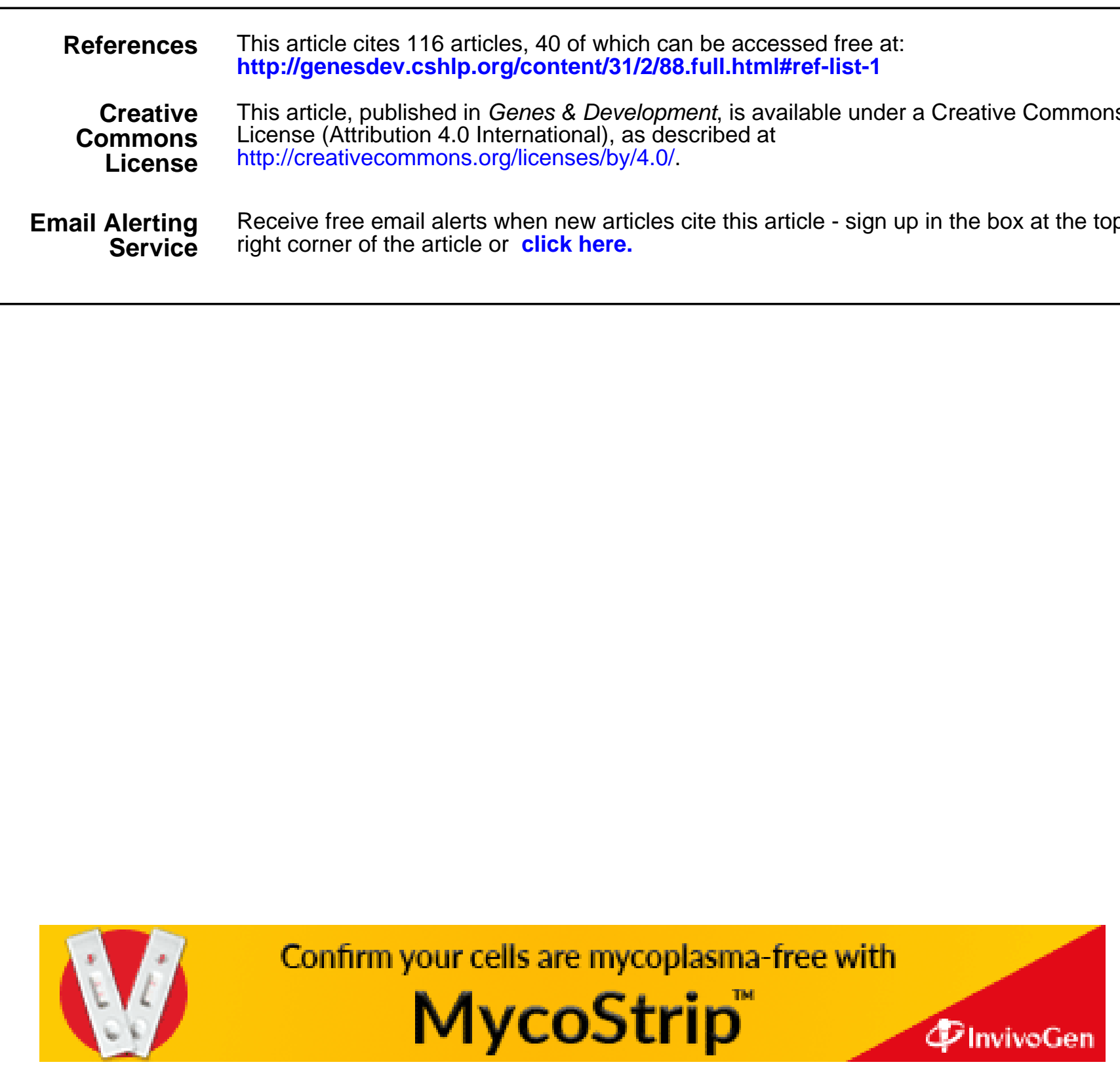

(C) 2017 Zinder and Lima; Published by Cold Spring Harbor Laboratory Press 